Article

\title{
DFT Study of Si/Al Ratio and Confinement Effects on the Energetics and Vibrational Properties of some Aza-Aromatic Molecules Adsorbed on H-ZSM-5 Zeolite
}

\author{
Martine Castellà-Ventura ${ }^{1}$, Alain Moissette ${ }^{2}$ (D) and Emile Kassab ${ }^{1, *(D)}$ \\ 1 Laboratoire de Chimie Théorique, UMR 7616 CNRS, Sorbonne Université, 4 place Jussieu, \\ 75252 Paris, France; martine.ventura@lct.jussieu.fr \\ 2 Laboratoire de Spectrochimie Infrarouge et Raman, UMR 8516 CNRS, Université Lille, \\ 59650 Villeneuve d'Ascq, France; alain.moissette@univ-lille.fr \\ * Correspondence: emile.kassab@lct.jussieu.fr; Tel.: +33-1-44-27-75-08
}

Received: 4 July 2020; Accepted: 8 September 2020; Published: 10 September 2020

\begin{abstract}
The Si/Al ratio and confinement effects of zeolite framework on energetics and vibrational frequencies of pyridine and 4,4'-bipyridine adsorbed on Brønsted acid sites in the straight channel of H-ZSM- 5 are investigated by DFT calculations at the B3LYP and M06-2X+D3 levels. The straight channel of H-ZSM-5 is simulated by a cluster of 32 tetrahedral centers covering the intersection between straight and zigzag channels. Pyridine and 4,4'-bipyridine adsorption at two different sites in the intersection (open region) and/or in the narrow region situated between two intersections (closed region) is studied. For two $\mathrm{Si} / \mathrm{Al}$ ratios $(31,15)$, the ion pair complexes formed by proton transfer upon pyridine and 4,4'-bipyridine adsorption in the open region and for the first time in the closed region are characterized. Our results indicate: (i) the stability for all adsorption complexes is essentially governed by the dispersive van der Waals interactions and the open region is energetically more favorable than the closed region owing to the predominance of the dispersive interactions over the steric constraints exerted by the confinement effects; (ii) as the Al centers are sufficiently spaced apart, $\mathrm{Si} / \mathrm{Al}$ ratio does not influence pyridine adsorption energy, but significantly affects the adsorption energies and the relative stability of 4,4'-bipyridine complexes; (iii) neither $\mathrm{Si} / \mathrm{Al}$ ratio nor confinement significantly influence pyridine and 4, $4^{\prime}$-bipyridine vibrational frequencies within their complexes.
\end{abstract}

Keywords: H-ZSM-5 zeolite; aza-aromatics; proton transfer; Si/Al ratio effect; confinement effect; DFT-D calculations

\section{Introduction}

Zeolites represent one of the most important classes of heterogeneous solid acid catalysts. They offer a versatile class of shape selective catalysts for important chemical processes such as petroleum cracking and reforming [1,2]. The catalytic activity of zeolites is related to the Brønsted acidity of bridging hydroxyl groups Si-OH-Al. Many catalytic processes in zeolites are activated by proton transfer from Brønsted acid sites (BAS). These sites are strong enough to adsorb guest molecules by hydrogen bonding interactions initiating a series of reactions that can lead to the formation of new species. Because of its importance in industrial catalytic applications [3,4], the Brønsted acidity of zeolites has widely been investigated with experimental [5-11] and theoretical methods [12-26]. Experimentally, several techniques such as IR and Raman [5-8], NMR [9,10], and neutron-scattering [11] studies have been used to characterize the structure and interactions at a molecular level, often with somewhat 
inconclusive results. On the theoretical side, there is a full range of modeling techniques based on quantum mechanical methods such as cluster approach [12-15], embedded cluster ONIOM [16-21], and periodic [22-26] DFT calculations. Quantum-chemical calculations on small clusters have long been the staple for modeling zeolite electronic structure and the acidity of Brønsted sites, and its interaction with small basic molecules. For larger molecules such as aromatic species, with dimension comparable to the opening pores of zeolites such as H-ZSM-5, the small clusters ignore long range electrostatic interactions and the long range electron correlation effects that give rise to dispersion forces and some hydrogen bonding. In addition small clusters lack the steric constraints which characterize adsorption in zeolites, because the small cluster may not represent the zeolite cavity and thus the effects of the zeolite framework are not taken into account. Thus, the cluster model of protonic zeolites, in order to be reliable, should include the cavity. In this work, we have studied the adsorption of two aromatic molecules pyridine (PY) and 4,4'-bipyridine (44BPY) on the Brønsted acid sites of H-ZSM-5 zeolite. Because of their size, which are close to that of the pores of H-ZSM-5 cavities, they interact with the zeolite by two types of interaction: covalent interactions with the Brønsted acid sites Si-OH-Al, and non-covalent interactions (van der Waals) with the atoms of the wall cavity, responsible for the confinement effects. It is well known that PY is a probe molecule that has been used for a very long time in IR and Raman spectrometries [5-8] to characterize and differentiate Lewis acid sites from Brønsted acid sites. 44BPY is a very interesting bidentate molecule of strong basicity, which possibly allows to simultaneously characterize two Brønsted acid sites located in two different environments in the straight channel of $\mathrm{H}-\mathrm{ZSM}-5$, and consequently to determine the relative position of two $\mathrm{Al}$ atoms when there is a double proton transfer. Some previous theoretical studies on the adsorption of PY in H-ZSM-5 using realistic cluster calculations including in the most cases only one $\mathrm{Al}$ atom located at the specific region in H-ZSM-5 cavity have also been reported [17-19,24,26]. All of these theoretical studies were only focused on the energetic properties of pyridine adsorption; none of them was reported on the vibrational properties in the zeolite cavity. In addition, regarding the adsorption of 44BPY in zeolites, except our previous works [27-29], no study has been conducted to date. The novelty of the present study with respect to our previous work consists of the fact that we have investigated simultaneously, for the first time, the Si/Al ratio and confinement effects of the zeolite framework of H-ZSM-5 on the energetics and vibrational properties of PY and 44BPY by employing a realistic cluster model with two Si/Al ratios (15 and 31) to represent the straight channel of H-ZSM-5 and by using Density Functional Theory including dispersion interaction (DFT-D). For the first time, pyridine adsorption has been characterized in two regions of H-ZSM-5 cavity: in the intersection region (open region), and in the straight channel region between two intersections (closed region). In this latter region, the pyridine molecules were also detected for the first time by single-crystal X-ray diffraction [30]. In the case of 44BPY, the mono and diprotonated forms were observed in the H-ZSM- 5 zeolite by Raman spectrometry [7,29] and confirmed by our previous study for $\mathrm{Si} / \mathrm{Al}=15$ [29]. Our present theoretical results have been compared to available experimental data.

\section{Theoretical Calculations}

H-ZSM- 5 has been chosen for the present study for a number of reasons. Besides, it being an active acid catalyst, the medium-sized opening pores of its straight channels are comparable to the dimension of some aromatic compounds. A straight channel of H-ZSM- 5 is simulated by a cluster of 32 tetrahedral centers (32T), extracted from the straight channel of a silicious crystallographic H-ZSM-5 structure (http://www.iza-structure.org/databases/). The dangling bonds are terminated by $\mathrm{H}$ atoms replacing the next crystallographic atoms. It consists of three 10-membered rings (10R) and covers the intersection between the straight channel and the zigzag channel (Figure 1). For the cluster of $\mathrm{Si} / \mathrm{Al}=31$, one $\mathrm{Al}$ atom is located either at the first 10R in the open region or at the third 10R in the closed region generating one Brønsted acid site to compensate the negative charge of the framework around the Al site. Thus, only monodentate adsorption complexes could be formed with PY or 44BPY ligand. For $\mathrm{Si} / \mathrm{Al}=15$ ratio, the $32 \mathrm{~T}$ cluster has two $\mathrm{Al}$ atoms, one located at first $10 \mathrm{R}$ in the open region 
and other at third 10R in the closed region. The distance between two Al sites is about $\sim 13.8 \AA$. The two protons compensate the negative charge of the framework around the two Al sites. Thus, both mono and bidentate adsorption complexes could be formed with 44BPY. It should be noted that our 32T cluster model was chosen to study in particular the confinement effect. Indeed, it is well adapted to the size of our bidentate ligand 4,4'-bipyridine, which is completely confined in our cluster, consequently the main interactions (covalent and non-covalent) are taken into account. Obviously, increasing of cluster size contributes to increase the adsorption energies of all complexes.



Figure 1. Schematic representation of the straight channel of H-ZSM-5. Open and closed regions of the $32 \mathrm{~T}$ clusters are denoted by "op" and " $\mathrm{cl}^{\prime}$, respectively.

In the DFT optimization calculations, B3LYP functional combined with the standard $6-31+\mathrm{G}^{*}$ basis set were used to characterize the structures and the vibrational frequencies of PY and 44BPY adsorption complexes implicated in the proton transfer reaction. The choice of this method and of this basis set is based on our results obtained by different approaches discussed in detail in our previous article [29]. The optimization criteria adopted are such that the convergences were considered to be reached when predicted change in energy is less than $10^{-6}$ Hartree and the changes in the structure are negligible. Since our systems contain lots of tetrahedral centers, we used for all calculations the same integration UltraFine Grid [31]. It should be mentioned that in order to maintain the crystallographic structure, the coordinates of the atoms on the edge of the cluster model are frozen. The calculated frequencies for PY and 44BPY species studied here were scaled by scaling factors of $\sim 0.968$ and $\sim 0.978$, respectively, determined to give the best agreement with experimental anharmonic frequencies. Since both B3LYP and M06-2X functionals give almost the same optimized structures for the adsorption complexes in the case of $\mathrm{Si} / \mathrm{Al}=15$ considered in our previous work [29], single-point energies were calculated on the B3LYP optimized structures at the level of M06-2X-D3 functional that implicitly accounts for short and medium-range dispersion interactions [32], with the addition of Grimme's long-range D3 dispersion corrections [33]. The adsorption energy $\mathrm{E}_{\mathrm{ads}}$ was computed as the difference between the energy of the optimized adsorption complex, and the sum of the energies of the optimized isolated molecule and the optimized bare 32T cluster. The B3LYP and M06-2X calculations of $E_{\text {ads }}$ were systematically corrected for the basis set superposition error (BSSE) [34]. As the B3LYP functional does not account for 
dispersion forces, the dispersive van der Waals ( $\mathrm{vdW}$ ) interactions were estimated by the dispersion energy $\left(E_{\text {disp }}\right)$ obtained as the difference between the adsorption energies calculated with both B3LYP and M06-2X-D3 functionals. All calculations were performed with the Gaussian09 package [31].

\section{Results and Discussion}

\subsection{Structure and Energetic Analysis}

The B3LYP optimized structures of adsorption complexes formed upon adsorption of PY and 44BPY on BAS are illustrated in Figures 2 and 3, respectively, and listed in Table 1 (see also Supplementary Materials). In the case of the interaction of PY with BAS located either in the open region or in the closed region, our calculation results show that the B3LYP geometry optimization of this system leads to the formation of monodentate ion pair complex $\mathrm{PYH}^{+} / 32 \mathrm{~T}^{-}$by transferring the acidic proton to the ligand whatever the Si/Al ratio. The $\mathrm{PYH}^{+}$pyridinium remains close to the $\mathrm{AlO}_{4}$ tetrahedron, forming a strong hydrogen bond $\mathrm{O} \ldots \mathrm{H}-\mathrm{N}$ with the oxygen atom. In the open region, the hydrogen bound is almost linear $\left(\mathrm{O} \ldots \mathrm{H}-\mathrm{N}=172^{\circ}\right)$, while, in the closed region, due to the steric constraints, the hydrogen bond elongates a little and moves away from linearity, $\left(\mathrm{O} \ldots \mathrm{H}-\mathrm{N}=153^{\circ}\right)$. As can be seen in Table 1 , the $\mathrm{Si} / \mathrm{Al}$ ratio has no effect on the structures of the pyridine adsorption complexes. Indeed, in the case of the $\mathrm{Si} / \mathrm{Al}=15$ ratio, the position of the second $\mathrm{Al}$ atom is very far from the cation $\mathrm{PYH}^{+}$. For the optimized structures of the 44BPY adsorption complexes, the situation is a little different, since the adsorbed molecule occupies the two straight channel regions. In the case of monodentate ion pair complex $44 \mathrm{BPYH}^{+} / 32 \mathrm{~T}^{-}$, when pyridinium ring is in one region, the pyridyl ring is in another region of ionic or covalent character depending on the $\mathrm{Si} / \mathrm{Al}$ ratio of 15 or 31, respectively. Therefore, the effect of the $\mathrm{Si} / \mathrm{Al}$ ratio could not be negligible on some intermolecular geometrical parameters. In the open region, the monodentate adsorption complexes are formed by a strong hydrogen bond $\mathrm{O} \ldots \mathrm{H}-\mathrm{N}$, a little longer and much less linear than in the case of PY complexes. On the other hand, the hydrogen bond is more bent in the case of the cluster of $\mathrm{Si} / \mathrm{Al}=31\left(\mathrm{O} \ldots \mathrm{H}-\mathrm{N}=138^{\circ}\right)$ where the pyridyl ring is in front of $\mathrm{SiO}_{4}$ tetrahedron than in the case of $\mathrm{Si} / \mathrm{Al}=15$ where the pyridyl ring is in front of acidic proton of $\mathrm{AlO}_{4}$ tetrahedron $\left(\mathrm{O} \ldots \mathrm{H}-\mathrm{N}=148^{\circ}\right)$. In the closed region, the proton transfer between BAS and 44BPY leading to the formation of the ion pair complex does not occur spontaneously. It passes through the formation of the slightly stable hydrogen bound complex, and a very low barrier that can be crossed by the vibrational zero point energy $[15,29]$. In this case, the $44 \mathrm{BPYH}^{+}$cation within the $10 \mathrm{R}$ channel moves away from $\mathrm{AlO}_{4}$ tetrahedron. The optimized $\mathrm{O}$... H-N distance is $2.88 \AA$. Therefore, it is not complexed to the zeolite framework by a strong hydrogen bond, but is rather considered as a solvated ion in the zeolite cavity. Indeed, the molecule adjusts its position and orientation in order to reduce the steric constraints of the confinement effects of the zeolite framework and thus tends to become parallel to the 10R channel axis (denoted (z) in Figure 1). It should be noted that for $\mathrm{Si} / \mathrm{Al}=15$, the bidentate $44 \mathrm{BPYH}_{2}{ }^{2+} / 32 \mathrm{~T}^{2-}$ ion pair complex could be formed by the transfer of the second proton (with some barrier) from either the open region or the closed region to the $44 \mathrm{BPYH}^{+}$cation within closed or open monodentate ion pair complex, respectively [29]. In this bidentate ion pair complex, the position of each pyridinium cation is almost similar to that of the corresponding monodentate ion pair complex [29]. As a consequence, the $44 \mathrm{BPYH}_{2}{ }^{2+}$ dication must bend around the C-C interring axis. 



Figure 2. PY adsorption complexes in the open and closed regions of the $32 \mathrm{~T}$ cluster for $\mathrm{Si} / \mathrm{Al}=15$.
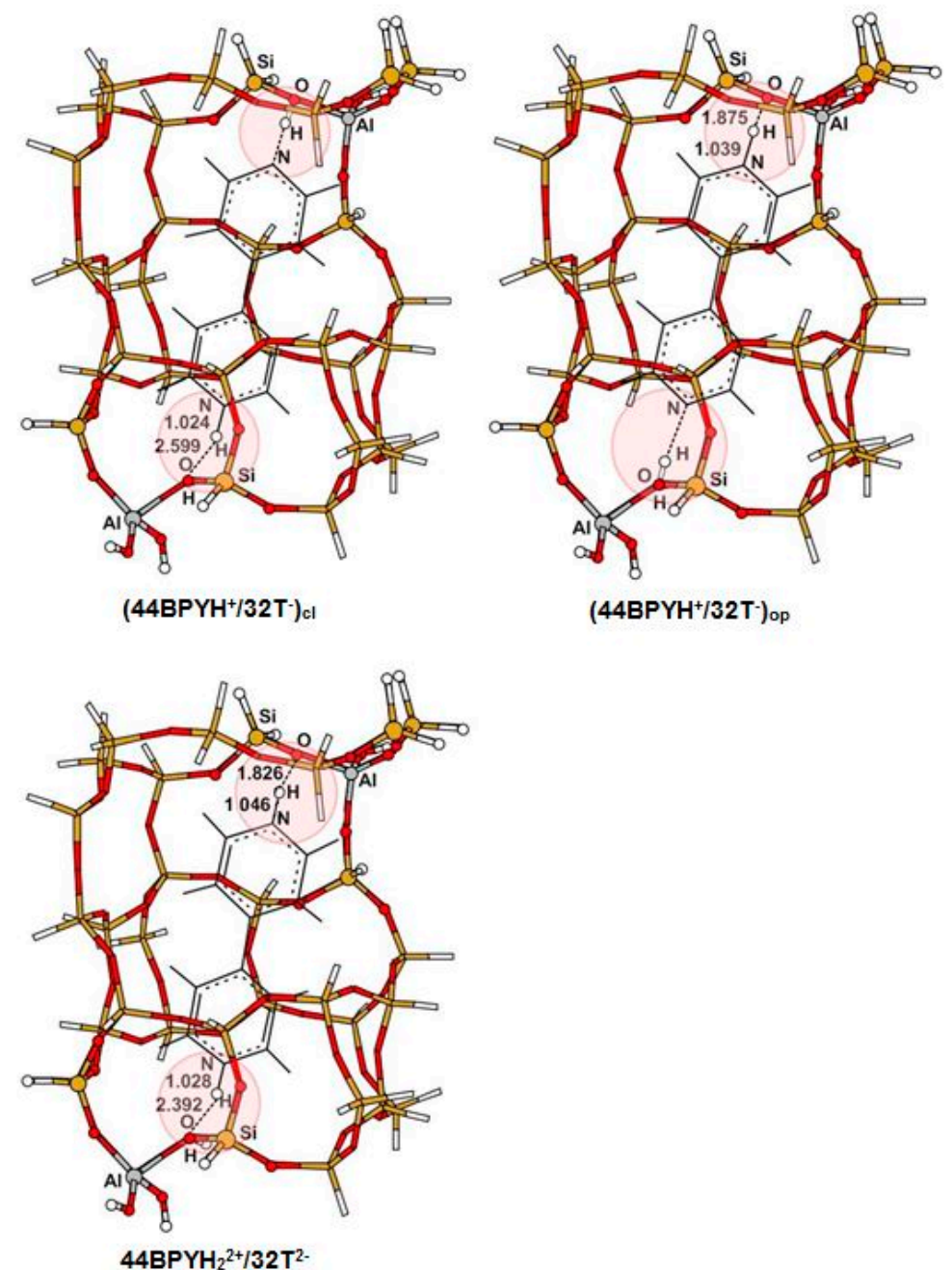

Figure 3. 44BPY adsorption complexes in the open and closed regions of the $32 \mathrm{~T}$ cluster for $\mathrm{Si} / \mathrm{Al}=15$. 
Table 1. B3LYP optimized intermolecular geometrical parameters of PY and 44BPY adsorption complexes formed in the open and closed regions of the $32 \mathrm{~T}$ cluster for $\mathrm{Si} / \mathrm{Al}=15$ and 31 .

\begin{tabular}{|c|c|c|c|c|c|c|c|}
\hline \multirow{3}{*}{$\mathrm{Si} / \mathrm{Al}$} & \multirow{3}{*}{$\begin{array}{l}\text { Geometrical } \\
\text { Parameters }\end{array}$} & \multirow{2}{*}{\multicolumn{2}{|c|}{$\begin{array}{c}\mathrm{PY}+32 \mathrm{~T} \\
\mathrm{PYH}^{+} / 32 \mathrm{~T}^{-}\end{array}$}} & \multicolumn{4}{|c|}{$44 B P Y+32 T$} \\
\hline & & & & \multicolumn{2}{|c|}{$44 \mathrm{BPYH}^{+} / 32 \mathrm{~T}^{-}$} & \multicolumn{2}{|c|}{$44 \mathrm{BPYH}_{2}{ }^{2+} / 32 \mathrm{~T}^{2}$} \\
\hline & & Open & Closed & Open & Closed & Open & Closed \\
\hline \multirow{4}{*}{$\begin{array}{c}31 \\
(31 \mathrm{Si}, 1 \mathrm{Al})\end{array}$} & $\mathrm{NH}$ & 1.060 & 1.052 & 1.036 & 1.024 & & \\
\hline & $\mathrm{OH}$ & 1.646 & 1.717 & 1.884 & 2.596 & & \\
\hline & $\mathrm{NO}$ & 2.698 & 2.698 & 2.744 & 3.301 & & \\
\hline & $\mathrm{NHO}$ & 171.4 & 153.3 & 138.2 & 125.8 & & \\
\hline \multirow{4}{*}{$\begin{array}{c}15 \\
(30 \mathrm{Si}, 2 \mathrm{Al})\end{array}$} & $\mathrm{NH}$ & 1.060 & 1.052 & 1.039 & 1.024 & 1.046 & 1.028 \\
\hline & $\mathrm{OH}$ & 1.642 & 1.711 & 1.875 & 2.599 & 1.826 & 2.392 \\
\hline & $\mathrm{NO}$ & 2.696 & 2.695 & 2.781 & 3.316 & 2.760 & 3.147 \\
\hline & $\mathrm{NHO}$ & 172.0 & 153.8 & 143.7 & 126.9 & 146.7 & 129.5 \\
\hline
\end{tabular}

The corrected adsorption energies ( $\left.\mathrm{E}_{\mathrm{ads}}\right)$ of PY and 44BPY ligands calculated at the B3LYP and M06-2X-D3 levels are listed in Table 2. For all adsorption complexes considered here, $\mathrm{E}_{\text {ads }}$ values calculated at the B3LYP level are much lower compared to the M062X-D3 values. At the B3LYP level, except for the adsorption of PY in the open region where there is free space available, PY and 44BPY adsorbed on the BAS of the $32 \mathrm{~T}$ cluster model are not or little bounded. This is not surprising, owing to the lack of dispersive vdW interactions in the B3LYP functional and the importance of the steric effect due to the lack of free space, especially in the closed region. However, B3LYP calculations allow us to evaluate the steric effect. For example, the destabilization due to steric constraints of the adsorbed PY in the closed region can be approximately estimated as the B3LYP interaction energy difference between the closed and open regions (19.5 kcal/mol). At the M06-2X-D3 level, due to the dispersive $\mathrm{vdW}$ interactions that are accounted for at this level, the stability of the two ion pair complexes formed in the open and closed regions increases considerably, especially in the closed region where the dispersion energy $\mathrm{E}_{\mathrm{disp}}$ is calculated to be more than twice higher $(\sim 25.0 \mathrm{kcal} / \mathrm{mol})$ than that of the open region ( $11.9 \mathrm{kcal} / \mathrm{mol})$. The dispersive vdW interactions represent $\sim 34 \%$ and $\sim 88 \%$ of the total corrected adsorption energies of $\sim-35.2$ and $\sim-28.4 \mathrm{kcal} / \mathrm{mol}$ for PY adsorbed in the open and closed regions, respectively. The adsorption energy difference between both complexes decreases from $19.5 \mathrm{kcal} / \mathrm{mol}$ calculated at the B3LYP level to $6.8 \mathrm{kcal} / \mathrm{mol}$ estimated by M06-2X-D3 calculations. It should be emphasized that whatever the level of calculation, the $\mathrm{Si} / \mathrm{Al}$ ratio has no influence neither on the total corrected adsorption energy nor on the dispersion energy of pyridine because the $\mathrm{Al}$ sites are spaced far enough apart to have properties of isolated sites.

Table 2. BSSE corrected adsorption energies $\left(E_{a d s}\right)$, and estimated dispersion energies $\left(E_{\text {disp }}\right)$ for PY and 44BPY adsorption complexes formed in the open (op) and closed (cl) regions for $\mathrm{Si} / \mathrm{Al}=15$ and 31, calculated at B3LYP and MO6-2X-D3//B3LYP levels. All energies are in kcal/mol.

\begin{tabular}{|c|c|c|c|c|c|c|}
\hline \multirow{3}{*}{$\begin{array}{l}\text { Adsorption } \\
\text { Complexes }\end{array}$} & \multicolumn{3}{|c|}{$\mathrm{Si} / \mathrm{Al}=15$} & \multicolumn{3}{|c|}{$\mathrm{Si} / \mathrm{Al}=31$} \\
\hline & \multicolumn{2}{|c|}{$\mathrm{E}_{\text {ads }}$} & \multirow[t]{2}{*}{$E_{\text {disp }}{ }^{1}$} & \multicolumn{2}{|c|}{$\mathrm{E}_{\mathrm{ads}}$} & \multirow[t]{2}{*}{$E_{\text {disp }}{ }^{1}$} \\
\hline & B3LYP & M06-2X-D3 & & B3LYP & M06-2X-D3 & \\
\hline$\left(\mathrm{PYH}^{+} / 32 \mathrm{~T}^{-}\right)_{\mathrm{op}}$ & -23.2 & -35.2 & -12.0 & -23.5 & -35.3 & -11.8 \\
\hline$\left(\mathrm{PYH}^{+} / 32 \mathrm{~T}^{-}\right)_{\mathrm{cl}}$ & -3.7 & -28.4 & -24.7 & -3.1 & -28.5 & -25.4 \\
\hline$\left(44 \mathrm{BPYH}^{+} / 32 \mathrm{~T}^{-}\right)_{\mathrm{op}}$ & -0.7 & -44.0 & -43.3 & +3.9 & -36.8 & -40.7 \\
\hline$\left(44 \mathrm{BPYH}^{+} / 32 \mathrm{~T}^{-}\right)_{\mathrm{cl}}$ & +2.1 & -39.0 & -41.1 & +12.0 & -25.5 & -37.5 \\
\hline $44 \mathrm{BPYH}_{2}{ }^{2+} / 32 \mathrm{~T}^{2-}$ & -3.2 & -44.2 & -41.0 & & & \\
\hline
\end{tabular}


In the case of the 44BPY adsorption in the straight channel of H-ZSM-5 zeolite, since it is a large bidentate ligand, there is a large molecule/zeolite surface contact area. Obviously, the confinement effect is much more important for 44BPY than for PY. The 44BPY bidentate ligand could thus interact with two Brønsted acid sites associated with two Al atoms quite apart from each other and located in the open and closed regions. Consequently, the $\mathrm{Si} / \mathrm{Al}$ ratio could have effects on the energetic properties of 44BPY adsorption. For Si/Al = 31, when 44BPY interacts with the BAS, only a monodentate ion pair complex is formed either in the open region, or in the closed region depending on the position of $\mathrm{Al}$ site. The stability of 44BPY adsorption complexes are completely due to the dispersive vdW interactions executed by confinement effect of the zeolite framework. As in the case of PY adsorption, the corrected adsorption energy calculated at the M062X-D3 level of $36.8 \mathrm{kcal} / \mathrm{mol}$ for 44BPY adsorbed in the open region is larger by $11.3 \mathrm{kcal} / \mathrm{mol}$ than that calculated for 44BPY adsorbed in the closed region. This relative stability of $44 \mathrm{BPY}$ adsorption complexes is mainly due to the steric effect, which is more important in the case of the closed region.

For $\mathrm{Si} / \mathrm{Al}=15$, the $32 \mathrm{~T}$ cluster has two BAS located in two different regions. Thus, three types of adsorption complexes are involved in the proton transfer from BAS of zeolite to 44BPY ligand. In addition to the two monodentate ion pair complexes, a bidentate ion pair complex is formed by the transfer of the second proton to one or the other monodentate ion pair complex. The stability of these complexes is also entirely governed by the confinement effect. The adsorption energies of these complexes increase in the following order: $\left(44 \mathrm{BPYH}^{+} / 32 \mathrm{~T}^{-}\right)_{\mathrm{cl}}<\left(44 \mathrm{BPYH}^{+} / 32 \mathrm{~T}^{-}\right)_{\mathrm{op}}<44 \mathrm{BPYH}_{2}{ }^{2+} / 32 \mathrm{~T}^{2-}$. The mechanism of the double proton transfer reaction leading to the formation of the bidentate ion pair complex was largely discussed in our previous papers [27-29]. In comparison with $\mathrm{Si} / \mathrm{Al}=31$, the corrected adsorption energies are larger, especially for closed monodentate ion pair complex and the relative stability of these complexes is smaller. It does not exceed $5.2 \mathrm{kcal} / \mathrm{mol}$. The high stability of the adsorption complexes for $\mathrm{Si} / \mathrm{Al}=15$ with respect to that for $\mathrm{Si} / \mathrm{Al}=31$ is due to the fact that, in the case of $\mathrm{Si} / \mathrm{Al}=15$, the second pyridyl ring of the monodentate ion pair complexes is not far from the second Brønsted acid site to interact with it.

\subsection{Vibrational Frequencies}

In the 1400-1700 $\mathrm{cm}^{-1}$ spectral region, among the four combined ring stretching and in-plane $\mathrm{CH}$ and/or $\mathrm{NH}$ bending vibrational modes, $19 \mathrm{~b}$ and $8 \mathrm{~b}$ modes, and to a lesser extend $8 \mathrm{a}$ mode, allow distinguishing the different adsorption complexes (hydrogen bond, Lewis and ion pair complexes) [5,35]. The fourth mode 19a has the same frequency in all complexes. In the spectral region around $1000 \mathrm{~cm}^{-1}$, the two combined in-plane ring deformation and ring stretching modes 12 and 1 allow also differentiating the PY adsorption complexes [36].

The B3LYP calculated vibrational frequencies of PY free or adsorbed within the ion pair complexes formed in the open and closed regions of the 32T cluster for both Si/Al ratios (15 and 31) are listed in Table 3 together with the available experimental data. The experimental and B3LYP frequency shifts on going from PY to protonated species $\mathrm{PYH}^{+}$are also reported in Table 3. 
Table 3. Experimental and B3LYP calculated frequencies $\left(\mathrm{cm}^{-1}\right)$ of in-plane modes in the $1400-1700 \mathrm{~cm}^{-1}$ spectral region and around $1000 \mathrm{~cm}^{-1}$ for free PY and $\mathrm{PYH}^{+}$complexed to H-ZSM-5.

\begin{tabular}{|c|c|c|c|c|c|c|c|}
\hline \multirow{3}{*}{$\begin{array}{l}\text { Vibrational } \\
\text { Modes }^{1}\end{array}$} & \multicolumn{2}{|c|}{ PY } & \multicolumn{5}{|c|}{$\mathrm{PYH}^{+} / 32 \mathrm{~T}^{-}$} \\
\hline & \multirow{2}{*}{$\operatorname{Exp}^{2}$} & \multirow[b]{2}{*}{ Calc $^{3}$} & \multirow[b]{2}{*}{$\operatorname{Exp}^{4,5}$} & \multicolumn{2}{|c|}{ Closed } & \multicolumn{2}{|c|}{ Open } \\
\hline & & & & $\begin{array}{c}\text { Si } / \mathrm{Al}=15 \\
\text { Calc } 3,5\end{array}$ & $\begin{array}{c}\mathrm{Si} / \mathrm{Al}=31 \\
\text { Calc }^{3,5}\end{array}$ & $\begin{array}{c}\mathrm{Si} / \mathrm{Al}=15 \\
\text { Calc }\end{array}$ & $\begin{array}{c}\mathrm{Si} / \mathrm{Al}=31 \\
\text { Calc }^{3,5}\end{array}$ \\
\hline 1 & 991 & 987 & $1007(+16)-1015(+24)$ & $994(+7)$ & $990(+4)$ & $994(+7)$ & $990(+4)$ \\
\hline 12 & 1032 & 1021 & $1025(-7)-1035(+3)$ & $1013(-8)$ & $1021(-1)$ & $1013(-8)$ & $1021(0)$ \\
\hline $19 b$ & 1442 & 1446 & $1530(+88)-1550(+108)$ & $1560(+114)$ & $1557(+111)$ & $1560(+115)$ & $1556(+111)$ \\
\hline $19 \mathrm{a}$ & 1483 & 1487 & $1485(+2)-1500(+17)$ & $1485(-2)$ & $1493(+6)$ & $1485(-2)$ & $1493(+7)$ \\
\hline $8 b$ & 1581 & 1591 & $1630(+40)-1640(+50)$ & $1661(+70)$ & $1645(+54)$ & $1661(+70)$ & $1645(+54)$ \\
\hline $8 \mathrm{a}$ & 1590 & 1595 & $1608(+27)-1623(+42)$ & $1630(+35)$ & $1636(+40)$ & $1630(+35)$ & $1635(+40)$ \\
\hline
\end{tabular}

In general, whatever the cluster considered ( $\mathrm{Si} / \mathrm{Al}=15$ or 31 , open or closed region), a good agreement is obtained between the scaled frequencies and the experimental values for free and adsorbed PY. The frequency shifts on going from free $\mathrm{PY}$ to $\mathrm{PYH}^{+}$within the ion pair complexes are also well calculated. It is to be noted that these present results obtained with the $32 \mathrm{~T}$ realistic cluster are quite similar to those obtained previously with smaller $12 \mathrm{~T}$ cluster models of $\mathrm{Si} / \mathrm{Al}=2$ [15]. For a given region, whatever the $\mathrm{Si} / \mathrm{Al}$ ratio, the frequencies of $\mathrm{PYH}^{+}$within the ion pair complexes are identical. For a given $\mathrm{Si} / \mathrm{Al}$ ratio, whatever the region considered, the frequencies of $\mathrm{PYH}^{+}$are only slightly different; they differ by only $8 \pm 5 \mathrm{~cm}^{-1}$. Thus, the vibrational modes of adsorbed PY are essentially of local nature; they depend neither on the $\mathrm{Si} / \mathrm{Al}$ ratio nor on the confinement. In the spectral range between 1400 and $1700 \mathrm{~cm}^{-1}$, the three modes 19b, 8b, and $8 \mathrm{a}$ undergo significant positive shifts from PY free to PY adsorbed within the ion pair complexes. For modes $19 \mathrm{~b}$ and $8 \mathrm{~b}$, the large upward shift is principally due to a mechanical effect, i.e., to the coupling with the anharmonic in-plane $\mathrm{NH}$ bending vibration of same symmetry $\left(\sim 1405 \mathrm{~cm}^{-1}\right)$. It should be noted that the $8 \mathrm{~b}$ mode is calculated at higher frequency by $\sim 16 \mathrm{~cm}^{-1}$ in the open region with respect to the closed region. Indeed, in the closed region, mode $8 \mathrm{a}$ loses its original $\mathrm{A}_{1}$ symmetry $\left(\mathrm{C}_{2 \mathrm{v}}\right)$ upon adsorption, and becomes coupled to mode $8 \mathrm{~b}$ and to the in-plane $\mathrm{NH}$ bending vibration. It results that the contribution of the in-plane $\mathrm{NH}$ bending coordinate in the potential energy distribution [37] of mode $8 \mathrm{~b}$ is reduced, which leads to a decrease of its frequency, and consequently of its frequency shift. The significant positive shift upon adsorption calculated for mode $8 \mathrm{a}$ is mainly due to an electronic effect. This shift may be compared to those already observed upon quaternization of the pyridyl ring $[37,39]$. In the case of the closed region, the coupling with the in-plane $\mathrm{NH}$ bending vibration may explain the systematic larger vibrational shift with respect to the open region.

For 44BPY, as for PY, the two spectral regions particularly sensitive to the interaction with the adsorbing sites are located between 1400 and $1700 \mathrm{~cm}^{-1}$, and around $1000 \mathrm{~cm}^{-1}$. The comparison between the theoretical and experimental frequencies concerns only the vibrational modes observed in both spectral regions. Although the two pyridyl rings are located in different zeolite environments, the symmetry of both protonated species $44 \mathrm{BPYH}^{+}$and $44 \mathrm{BPYH}_{2}{ }^{2+}$ is only slightly affected. For $44 \mathrm{BPY}$ isolated and for $44 \mathrm{BPYH}_{2}{ }^{2+}$ free [37] or occluded in zeolite, these modes are the inter-ring stretching mode $(\Omega)$ and the A symmetry components of six pyridyl in-plane vibrations (the ring stretching and/or $\mathrm{CH}$ bending modes 8a, 19a, 9a and 18a, and the deformation ring modes 12 and 1 ). For $44 \mathrm{BPYH}^{+}$ free [37] or within H-ZSM-5, both components of these six modes are of A symmetry and so may be observed in the Raman spectra.

The B3LYP calculated frequencies of $44 \mathrm{BPYH}^{+}$within both monodentate ion pair complexes in the open and closed regions for both $\mathrm{Si} / \mathrm{Al}$ ratios (15 and 31) are compared with the available observed frequencies [29] in Table 4. The experimental and calculated frequency shifts on going from 44BPY to $44 \mathrm{BPYH}^{+}$within the ion pair complexes are also given in Table 4. 
Table 4. Experimental and B3LYP calculated frequencies $\left(\mathrm{cm}^{-1}\right)$ of in-plane modes in the $1400-1700 \mathrm{~cm}^{-1}$ spectral region and around $1000 \mathrm{~cm}^{-1}$ for free $44 \mathrm{BPY}$ and $44 \mathrm{BPYH}^{+}$complexed to H-ZSM-5.

\begin{tabular}{|c|c|c|c|c|c|c|c|}
\hline \multirow{3}{*}{$\begin{array}{l}\text { Vibrational } \\
\text { Modes }{ }^{1,2}\end{array}$} & \multicolumn{2}{|c|}{ 44BPY } & \multicolumn{5}{|c|}{$44 \mathrm{BPYH}^{+} / 32 \mathrm{~T}^{-}$} \\
\hline & \multirow{2}{*}{$\operatorname{Exp}^{3}$} & \multirow{2}{*}{ Calc $^{4}$} & \multirow{2}{*}{$\begin{array}{c}\operatorname{Exp}^{5,6} \\
\mathrm{Si} / \mathrm{Al}=100\end{array}$} & \multicolumn{2}{|c|}{ Closed } & \multicolumn{2}{|c|}{ Open } \\
\hline & & & & $\begin{array}{c}\mathrm{Si} / \mathrm{Al}=15 \\
\text { Calc } 4,6\end{array}$ & $\begin{array}{c}\mathrm{Si} / \mathrm{Al}=31 \\
\text { Calc }^{4,6}\end{array}$ & $\begin{array}{l}\mathrm{Si} / \mathrm{Al}=15 \\
\quad \text { Calc }\end{array}$ & $\begin{array}{c}\mathrm{Si} / \mathrm{Al}=31 \\
\text { Calc } 4,6\end{array}$ \\
\hline $6 b-B_{3}$ & 659 & 663 & $652(-7)$ & $647(-16)$ & $649(-14)$ & $645(-18)$ & $642(-21)$ \\
\hline $1-\mathrm{A}$ & 762 & 750 & $764(+2)$ & $754(+4)$ & $752(+2)$ & $751(+1)$ & $764(+14)$ \\
\hline $12-B_{1}$ & 989 & 988 & $994(+5)$ & $1004(+15)$ & $996(+8)$ & $1006(+18)$ & $999(+11)$ \\
\hline $12-\mathrm{A}$ & 1001 & 994 & $1012(+11)$ & $1017(+22)$ & $1018(+24)$ & $1021(+27)$ & $1016(+21)$ \\
\hline $18 a-B_{1}$ & 1075 & 1076 & $1064(-11)$ & $1075(-1)$ & $1076(0)$ & $1073(-3)$ & $1067(-9)$ \\
\hline $18 a-A$ & 1075 & 1079 & $1081(+6)$ & $1084(+5)$ & $1088(+9)$ & $1090(+11)$ & $1093(+14)$ \\
\hline $9 a-B_{1}$ & 1218 & 1228 & $1209(-9)$ & $1220(-8)$ & $1223(-5)$ & $1224(-4)$ & $1218(-10)$ \\
\hline 9a-A & 1216 & 1231 & $1222(+6)$ & $1242(+11)$ & $1243(+12)$ & $1240(+9)$ & $1238(+7)$ \\
\hline$\Omega-A$ & 1300 & 1291 & $1290(-10)$ & $1279(-12)$ & $1282(-9)$ & $1278(-13)$ & $1281(-10)$ \\
\hline $19 a-B_{1}$ & 1487 & 1496 & $1516(+29)$ & $1502(+6)$ & $1502(+6)$ & $1505(+9)$ & $1500(+4)$ \\
\hline $19 a-A$ & 1514 & 1516 & $1531(+17)$ & $1534(+18)$ & $1533(+17)$ & $1533(+16)$ & $1526(+10)$ \\
\hline $8 a-B_{1}$ & 1589 & 1608 & $1634(+45)$ & $1653(+45)$ & $1656(+48)$ & $1651(+43)$ & $1647(+39)$ \\
\hline $8 \mathrm{a}-\mathrm{A}$ & 1604 & 1614 & $1615(+11)$ & $1620(+5)$ & $1609(-6)$ & $1620(+6)$ & $1613(-1)$ \\
\hline
\end{tabular}

1 Notation used in Ref. [37]. ${ }^{2} \mathrm{D}_{2}$ symmetry for 44BPY. ${ }^{3}$ Ref. [39,40]. ${ }^{4}$ Scaling factor of $\sim 0.978 .{ }^{5}$ Ref. [29].

${ }^{6}$ Frequency shifts with respect to free $44 \mathrm{BPY}$ in parentheses.

In our previous exhaustive publication [29], we largely studied the vibrational properties of 44BPY adsorbed in the straight channel of H-ZSM-5 modeled by the same realistic cluster 32T of $\mathrm{Si} / \mathrm{Al}=15$. In the present study, we compare these vibrational results with those obtained with the cluster $32 \mathrm{~T}$ of $\mathrm{Si} / \mathrm{Al}=31$. As can be seen from Table 4, there is a satisfactory agreement between the scaled frequencies and the experimental values whatever the $\mathrm{Si} / \mathrm{Al}$ ratio (15 or 31) and the region (open or closed) for the monodentate ion pair complexes and for $\mathrm{Si} / \mathrm{Al}=15$ for the bidentate ion pair complex. The frequency shifts on going from 44BPY to both protonated species are also rather well calculated. For a given region, whatever the $\mathrm{Si} / \mathrm{Al}$ ratio, or for a given $\mathrm{Si} / \mathrm{Al}$ ratio, whatever the region considered, the frequencies of $44 \mathrm{BPYH}^{+}$within the ion pair complexes are quite similar (mean absolute difference of $4 \pm 3 \mathrm{~cm}^{-1}$ and $5 \pm 4 \mathrm{~cm}^{-1}$, respectively). As in the case of PY adsorption, the vibrational properties of 44BPY adsorption are of local nature and are quite insensitive to the confinement and to $\mathrm{Si} / \mathrm{Al}$ ratio.

For monodentate complexes, the high frequency component corresponding to the pyridinium ring of mode 8a, and for the bidentate complex, both components of mode 8a [29] are the most affected among the observed modes upon adsorption. This upward shift of $\sim 40 \mathrm{~cm}^{-1}$, comparable to PY one, is also explained by an electronic effect.

\section{Conclusions}

Based on the cluster DFT-D calculations of PY and 44BY adsorption at two different sites located in the open (intersection region) and/or closed regions (narrow region between two intersections) of H-ZSM-5, we analyzed how the confinement effects and Si/Al ratio influence the stability of ion pair adsorption complexes involved in the proton transfer reaction between Brønsted acid site and $\mathrm{PY}$ or/and 44BPY ligands. Our calculation results indicate that the open region is energetically more favorable than the closed region for all PY and 44BPY adsorption complexes owing to the predominance of the dispersive vdW interactions over steric constraints exerted by confinement effects. Except for ion pair adsorption complex of PY formed in the open region, the stability of all adsorption complexes considered in this study is completely governed by dispersive vdW interactions. For pyridine, the $\mathrm{Si} / \mathrm{Al}$ ratio has no influence neither on the total adsorption energy nor on the dispersion energy as the $\mathrm{Al}$ centers are spaced far enough apart to have properties of isolated sites. In contrast, the effect of $\mathrm{Si} / \mathrm{Al}$ ratio is significant on the adsorption energies and the relative stability of 44BPY adsorption complexes. Finally, unlike the adsorption energetics, our results clearly show that neither the effect of the Si/Al 
ratio nor the confinement effect has a significant influence on the vibrational frequencies of PY and 44BPY within their adsorption complexes.

Supplementary Materials: The following are available online at http://www.mdpi.com/2079-3197/8/3/81/s1, Figure S1: PY adsorption complexes in the open and closed regions of the $32 \mathrm{~T}$ cluster for $\mathrm{Si} / \mathrm{Al}=31$, Figure $\mathrm{S} 2$ : 44BPY adsorption complexes in the open and closed regions of the 32T cluster for $\mathrm{Si} / \mathrm{Al}=31$, Table S1: Cartesian coordinates of the structures of 32T clusters with $\mathrm{Si} / \mathrm{Al}=15$ and 31, and of all the PY and 44BPY adsorption complexes optimized at the B3LYP/6-31+G* level.

Author Contributions: All authors have contributed equally and have read and agreed to the published version of the manuscript.

Funding: This research received no external funding.

Acknowledgments: This work was performed using HPC resources from GENCI-CINES/IDRIS (Grants A0040807071 (2018), A0060807071 (2019)).

Conflicts of Interest: The authors declare no conflict of interest.

\section{References}

1. Bhattacharyya, K.G.; Talukdar, A.K. Catalysis in Petroleum and Petrochemical Industries; Narosa Publishing House: New Dehli, India, 2005.

2. Auerbach, S.M.; Carrado, K.A.; Dutta, P.K. Handbook of Zeolite Science and Technology; Marcel-Dekker: New York, NY, USA, 2003.

3. Chen, Y.H. Urea-SCR Technology for deNOx After Treatment of Diesel Exhausts; Springer: New York, NY, USA, 2014.

4. Martinez, C.; Corma, A. Inorganic molecular sieves: Preparation, Modification and Industrial Application in Catalytic Processes. Coor. Chem. Rev. 2011, 255, 1558-1580. [CrossRef]

5. Buzzoni, R.; Bordiga, S.; Ricchiardi, G.; Lamberti, C.; Zecchina, A.; Bellussi, G. Interaction of Pyridine with Acidic (H-ZSM5, H- $\beta$, H-MORD Zeolites) and Superacidic (H-Nafion Membrane) Systems: An IR Investigation. Langmuir 1996, 12, 930-940. [CrossRef]

6. Ferwerda, R.; van der Maas, J.H.; van Duijneveldt, F.B. Pyridine Adsorption onto Metal Oxides: An ab Initio Study of Model Systems. J. Mol. Catal. A Chem. 1996, 104, 319-328. [CrossRef]

7. Moissette, A.; Batonneau, Y.; Brémard, C. Conformation and Protonation of 2,2'-Bipyridine and 4,4'-Bipyridine in Acidic Aqueous Media and Acidic ZSM-5 Zeolites: A Raman Scattering Study. J. Am. Chem. Soc. 2001, 123, 12325-12334. [CrossRef]

8. Daniell, W.; Topsoe, N.-Y.; Knözinger, H. An FTIR Study of the Surface Acidity of USY Zeolites: Comparison of $\mathrm{CO}, \mathrm{CD}_{3} \mathrm{CN}$, and $\mathrm{C}_{5} \mathrm{H}_{5} \mathrm{~N}$ Probe Molecules. Langmuir 2001, 17, 6233-6239. [CrossRef]

9. Ehresmann, J.O.; Wang, W.; Herreros, B.; Luigi, D.-P.; Venkatraman, T.N.; Song, W.; Nicholas, J.B.; Haw, J.F. Theoretical and Experimental Investigation of the Effect of Proton Transfer on the ${ }^{27}$ Al MAS NMR Line Shapes of Zeolite-Adsorbate Complexes: An Independent Measure of Solid Acid Strength. J. Am. Chem. Soc. 2002, 124, 10868-10874. [CrossRef]

10. Dedecek, J.; Lucero, M.J.; Li, C.; Gao, F.; Klein, P.; Urbanova, M.; Tvaruzkova, Z.; Sazama, P.; Sklenak, S. Complex Analysis of the Aluminum Siting in the Framework of Silicon-Rich Zeolites. A Case Study on Ferrierites. J. Phys. Chem. C 2011, 115, 11056-11064. [CrossRef]

11. Jobic, H.; Czjzek, M.; van Santen, R.A. Interaction of Water with Hydroxyl Groups in H-Mordenite: A Neutron Inelastic Scattering Study. J. Phys. Chem. 1992, 96, 1540-1542. [CrossRef]

12. Sauer, J.; Ugliengo, P.; Garrone, E.; Saunders, V.R. Theoretical Study of van der Waals Complexes at Surface Sites in Comparison with the Experiment. Chem. Rev. 1994, 94, 2095-2160. [CrossRef]

13. Kassab, E.; Jessri, H.; Allavena, M.; White, D. Ab initio Calculations of Carbonyl Adsorption Complexes at Zeolitic Brønsted Sites Simulated by Model Clusters: Role of Modeling. J. Phys. Chem. A 1999, 103, 2766-2774. [CrossRef]

14. Rozanska, X.; van Santen, R.A.; Hutschka, F. A DFT Study of the Cracking Reaction of Thiophene Activated by Small Zeolitic Clusters. J. Catal. 2001, 200, 79-90. [CrossRef]

15. Castellà-Ventura, M.; Akacem, Y.; Kassab, E. Vibrational Analysis of Pyridine Adsorption on the Brønsted Acid Sites of Zeolites Based on Density Functional Cluster Calculations. J. Phys. Chem. C 2008, 112, 19045-19054.

16. Allavena, M.; Seiti, K.; Kassab, E.; Ferenczy, G.; Angyan, J.G. Quantum-Chemical Model Calculations on the Acidic Site of Zeolites Including Madelung-Potential Effects. Chem. Phys. Lett. 1990, 168, 461-467. [CrossRef] 
17. Yuan, S.; Shi, W.; Li, B.; Wang, J.; Jiao, H.; Li, Y.-W. Theoretical ONIOM2 Study on Pyridine Adsorption in the Channels and Intersection of ZSM-5. J. Phys. Chem. A 2005, 109, 2594-2601. [CrossRef]

18. Boekfa, B.; Choomwattana, S.; Khongpracha, P.; Limtrakul, J. Effects of the Zeolite Framework on the Adsorptions and Hydrogen-Exchange Reactions of Unsaturated Aliphatic, Aromatic, and Heterocyclic Compounds in ZSM-5 Zeolite: A Combination of Perturbation Theory (MP2) and a Newly Developed Density Functional Theory (M06-2X) in ONIOM Scheme. Langmuir 2009, 25, 12990-12999.

19. Patet, R.E.; Caratzoulas, S.; Vlachos, D.G. Adsorption in Zeolites Using Mechanically Embedded ONIOM Clusters. Phys. Chem. Chem. Phys. 2016, 18, 26094-26106. [CrossRef]

20. O'Malley, A.J.; Logsdail, A.J.; Sokol, A.A.; Catlow, C.R.A. Modelling Metal Centres, Acid Sites and Reaction Mechanisms in Microporous Catalysts. Faraday Discuss. 2016, 188, 235-255. [CrossRef]

21. Yi, X.; Li, G.; Huang, L.; Chu, Y.; Liu, Z.; Xia, H.; Zheng, A.; Deng, F. An NMR Scale for Measuring the Base Strength of Solid Catalysts with Pyrrole Probe: A Combined Solid-State NMR Experiment and Theoretical Calculation Study. J. Phys. Chem. C 2017, 121, 3887-3895. [CrossRef]

22. Nguyen, C.M.; Reyniers, M.F.; Marin, G.B. Theoretical Study of the Adsorption of the Butanol Isomers in H-ZSM-5. J. Phys. Chem. C 2011, 115, 8658-8669. [CrossRef]

23. Cheng, L.; Curtiss, L.A.; Assary, R.S.; Greeley, J.; Kerber, T.; Sauer, J. Adsorption and Diffusion of Fructose in Zeolite HZSM-5: Selection of Models and Methods for Computational Studies. J. Phys. Chem. C 2011, 115, 21785-21790. [CrossRef]

24. Boscoboinik, J.A.; Yu, X.; Emmez, E.; Yang, B.; Shaikhutdinov, S.; Fischer, F.D.; Sauer, J.; Freund, H.J. Interaction of Probe Molecules with Bridging Hydroxyls of Two-Dimensional Zeolites: A Surface Science Approach. J. Phys. Chem. C 2013, 117, 13547-13556. [CrossRef]

25. Liu, C.; Tranca, I.; van Santen, R.A.; Hensen, E.J.M.; Pidko, E.A. Scaling Relations for Acidity and Reactivity of Zeolites. J. Phys. Chem. C 2017, 121, 23520-23530. [CrossRef] [PubMed]

26. Boronat, M.; Corma, A. What Is Measured When Measuring Acidity in Zeolites with Probe Molecules? ACS Catal. 2019, 9, 1539-1548. [CrossRef] [PubMed]

27. Kassab, E.; Castellà-Ventura, M.; Akacem, Y. Theoretical Study of 4,4'-Bipyridine Adsorption on the Brønsted Acid Sites of H-ZSM-5 Zeolite. J. Phys. Chem. C 2009, 113, 20388-20395. [CrossRef]

28. Akacem, Y.; Castellà-Ventura, M.; Kassab, E. Theoretical Study of the Aluminum Distribution Effects on the Double Proton Transfer Mechanisms upon Adsorption of 4,4'-Bipyridine on H-ZSM-5. J. Phys. Chem. A 2012, 116, 1261-1271. [CrossRef]

29. Castellà-Ventura, M.; Moissette, A.; Kassab, E. A Theoretical Study of the Confinement Effects on the Energetics and Vibrational Properties of 4,4'-Bipyridine Adsorption on H-ZSM-5 Zeolite. Phys. Chem. Chem. Phys. 2018, 20, 6354-6364. [CrossRef]

30. Nishi, K.; Kamiya, N.; Yokomori, Y. Single-Crystal Structure of a Pyridine Sorption Complex of Zeolite HZSM-5 (H-MFI). Micropor. Mesopor. Mat. 2007, 101, 83-89. [CrossRef]

31. Frisch, M.J.; Trucks, G.W.; Schlegel, H.B.; Scuseria, G.E.; Robb, M.A.; Cheeseman, J.R.; Scalmani, G.; Barone, V.; Mennucci, B.; Petersson, G.A.; et al. Gaussian 09, Revision, D.01; Gaussian, Inc.: Wallingford, CT, USA, 2013.

32. Zhao, Y.; Schultz, N.E.; Truhlar, D.G. Design of Density Functionals by Combining the Method of Constraint Satisfaction with Parametrization for Thermochemistry, Thermochemical Kinetics, and Noncovalent Interactions. J. Chem. Theory Comput. 2006, 2, 364-382. [CrossRef]

33. Grimme, S. Semiempirical GGA-Type Density Functional Constructed with a Long-Range Dispersion Correction. J. Comput. Chem. 2006, 27, 1787-1799. [CrossRef]

34. Boys, S.F.; Bernardi, F. The Calculation of Small Molecular Interactions by the Differences of Separate Total Energies. Some Procedures with Reduced Errors. Mol. Phys. 1970, 19, 553-566. [CrossRef]

35. Parker, L.M.; Bibby, D.M.; Burns, G.R. Fourier-Transform Infrared Study of Pyridine Sorbed on Zeolite HY. J. Chem. Soc. Faraday Trans. 1991, 87, 3319-3323. [CrossRef]

36. Hendra, P.J.; Passingham, C.; Warnes, G.M.; Burch, R.; Rawlence, D.J. Fourier Transform Raman Spectroscopy in the Study of Species Adsorbed on Catalyst Surfaces. Chem. Phys. Lett. 1989, 164, 178-184. [CrossRef]

37. Castellà-Ventura, M.; Kassab, E. Vibrational Analysis of Some Transient Species Implicated in the Photoreduction of 4,4'-Bipyridine Based on ab Initio and Density Functional Calculations. J. Raman Spectrosc. 1998, 29, 511-536. [CrossRef]

38. Klots, T.D. Raman Vapor Spectrum and Vibrational Assignment for Pyridine. Spectrochim. Acta A 1998, 54, 1481-1498. [CrossRef] 
39. Ould-Moussa, L.; Poizat, O.; Castellà-Ventura, M.; Buntinx, G.; Kassab, E. Ab Initio Computations of the Geometrical, Electronic, and Vibrational Properties of the Ground State, the Anion Radical, and the N,N'-Dihydro Cation Radical of 4,4'-Bipyridine Compared to Transient Raman Spectra. J. Phys. Chem. 1996, 100, 2072-2082. [CrossRef]

40. Zhuang, Z.; Cheng, J.; Wang, X.; Zhao, B.; Han, X.; Luo, Y. Surface-Enhanced Raman Spectroscopy and Density Functional Theory Study on 4,4'-Bipyridine Molecule. Spectrochim. Acta A 2007, 67, 509-516. [CrossRef] [PubMed]

(C) 2020 by the authors. Licensee MDPI, Basel, Switzerland. This article is an open access article distributed under the terms and conditions of the Creative Commons Attribution (CC BY) license (http://creativecommons.org/licenses/by/4.0/). 